\title{
Serum High Sensitivity CRP (HsCRP) in Psoriasis
}

\author{
Dhat $V^{1}$, Murhe $S^{2}$, Sontakke $\mathbf{A}^{3}$ \\ ${ }^{1}$ Dr Vaishali Dhat, Associate Professor, Department of Biochemistry ${ }^{2}$ Mr Sumit Murhe, III MBBS Student, ${ }^{3}$ Dr Alka \\ Sontakke, Professor \& Head, Department of Biochemistry. All are affiliated with MIMER Medical College, Talegaon \\ Dabhade, Maharashtra, India
}

Address for correspondence: Dr Vaishali Dhat, Email: vaishdhat@yahoo.com

\begin{abstract}
Introduction: Psoriasis is a common and recurrent proliferative inflammatory skin disease that has been associated with abnormal plasma lipid metabolism and with high frequency of cardiovascular morbidity and mortality. Dyslipidemia in psoriatic patients make them more prone for CAD. Highly sensitive C reactive protein (HsCRP) is a recent and sensitive marker of the inflammation particularly in atherosclerotic changes. So the levels of hsCRP and lipid profile were evaluated in psoriatic patients. Material and Methods: The study included 35 psoriatic patients and 35 healthy age and sex matched controls. Both the groups were evaluated for serum lipid profile and HsCRP levels. Results: The study showed that there was a significant rise in the levels of hsCRP in patients of psoriasis as compared to the controls $(p<0.001)$ These psoriatic patients were also significantly dyslipidemic as compared to the controls. Conclusion: The study showed that psoriatic patients are more prone for atherosclerotic changes and CAD. Raised hsCRP can be considered as an added risk factor in Psoriatic patients with regard to coronary artery diseases. Special attention thus should be given if diagnosed earlier for lifestyle modification and exercise in these patients to minimize the atherosclerotic changes. Role of antioxidant supplementation needs further studies in patients of psoriasis.
\end{abstract}

Key words: Dyslipidemia, Psoriasis, hsCRP, Coronary artery disease

\section{Introduction}

Psoriasis is a common disease involving 125 million patients worldwide. Psoriasis causes significant disability in many individuals, especially women and young patients. About $80 \%$ of patients with psoriasis report that the disease has a negative impact on their lives for a variety of reasons, including physical symptoms, embarrassing physical appearance (particularly because it begins at "30 years of age in $60 \%$ of cases) helplessness, frustration, anger, anxiety, depression, and increased use of alcohol [1].

The cause of psoriasis is unknown, and its pathogenesis is not fully understood [2]. Psoriasis has a complex genetic predisposition and inheritance pattern, plus an environmental component. Recent studies implicate smoking and obesity as modifiable risk factors for psoriasis $[3,4]$.

The pathophysiology of psoriasis is incompletely

Manuscript received: $10^{\text {th }}$ July 2014

Reviewed: $12^{\text {th }}$ July 2014

Author Corrected: $24^{\text {th }}$ July 2014

Accepted for Publication: $5^{\text {th }}$ August 2014 understood but appears primarily due to a cell-mediated adaptive immune response involving cytokines of Th1 and Th17 pathway The leukocyte infiltrate in psoriatic skin lesions contains mainly $\mathrm{T}$ cells positive for clusters of CD-4 and CD-8[5,6].

Psoriasis is associated with several other disorders, including diabetes mellitus, the metabolic syndrome, cancer, CAD, etc [7]. Conditions that are known contributors to CAD-dyslipidemia, obesity, hypertension, and diabetes mellitus are more prevalent in patients with psoriasis than in the general population and patients with other dermatologic disorders $[8,9]$.

Dyslipidemia especially elevated low-density lipoprotein (LDL) cholesterol is common in patients with psoriasis, and the degree of elevation generally correlates with the severity of psoriasis. Lipid abnormalities often can be detected at the onset of psoriasis, suggesting that they may be genetically acquired $[8,10]$. 
CRP is a protein in the blood that is produced by the liver and tends to increase when there is inflammation in the body. CRP is an acute phase protein that appears in circulation in response to inflammatory cytokines \& serves as a non specific biomarker for systemic inflammation Research now indicates that CRP likely plays a direct active inflammatory role in blood vessels leading to development of atherosclerosis [11].

CRP levels may rise up to 3000 folds over circulating levels seen in apparently healthy individuals (normal CRP levels $10 \mathrm{mg} / \mathrm{L}$ ). Conventional CRP assays can not detect low levels of rise in CRP due to subtle causes of inflammation in various diseased states particularly cardiovascular disease [12].

The high sensitivity C-reactive protein (hsCRP) assay is a quantitative analysis of very low level of CRP in blood $(<10 \mathrm{mg} / \mathrm{L})$. This assay is being increasingly used as a marker of atherosclerosis which can lead to myocardial infarction and hence it is used as a predictor of myocardial infarction, future hypertension, stroke independent of abnormal lipid profile $[13,14]$.

In view of the above facts this study is designed to correlate dyslipidemia and hsCRP levels in patients of psoriasis.

\section{Material and Methods}

- Study design - Case Control study

- Study population - Sample for lipid profile and hsCRP in psoriatic patients attending the OPD of Dermatology Department.

- Place of study - Bhausaheb Sardesai Talegaon Rural Hospital, Talegaon Dabhade.

- Plan of study - Considering prevalence of cardiovascular disease in psoriatic patient as $23 \%$ (reported by other studies - investigative reportPsoriasis and metabolic syndrome. ACTA Dermatology, venerology 2007;87:506-509) with $95 \%$ confidence interval \& $80 \%$ power of test with $2 \%$ allowable errors the estimated sample was 35 patients of psoriasis.

- The subjects were categorized into two groups 1) Control - 35 healthy age $\&$ sex matched subjects

2) Cases - 35 patients of psoriasis

- Criteria for dyslipidemia: (according to Adult treatment panel 111 guidelines) [15]

$\checkmark$ Serum total cholesterol : $>200 \mathrm{mg} / \mathrm{dl}$

$\checkmark$ Serum total LDL : $>100 \mathrm{mg} / \mathrm{dl}$

$\checkmark \quad$ Serum total HDL : $<40 \mathrm{mg} / \mathrm{dl}$ $\checkmark$ Serum triacylglycerol : >150mg/dl

- If one or more of the above parameter is observed the individual will be considered as dyslipidemic.

\section{Inclusion criteria :}

Patients exclusively having psoriasis with no other major illness like diabetes mellitus, hypertension, CAD etc.

\section{- Exclusion criteria :}

Patients with known major illness like Hypertension, Ishemic heart disease, Diabetes mellitus, inflammatory disorders like SLE, rheumatoid arthritis \& hypotension, and other hormonal disorders.

1. HsCRP was estimated by turbidimetric method-

\section{Principle}

The CRP ultrasensitive is a quantitative turbidimetric test for the measurement of low levels of C-reactive protein (CRP) in human serum or plasma [16].

Latex coated with specific anti-human CRP is agglutinated when mixed with samples containing CRP. The agglutination causes an absorbance change depend upon the CRP contents of the patient sample that can be quantified by comparison from a calibrator of known CRP concentration.

The centre for disease control and prevention (CDC) and American heart association (AHA) recommended the following interpretation of hsCRP results-:

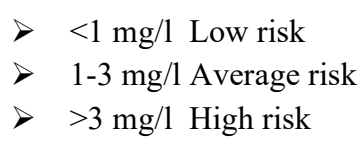

2. Lipid profile will be estimated by-

$\begin{array}{ll}\text { i. } & \text { Cholesterol :- Cholesterol oxidase } \\ \text { method [17] } & \\ \text { ii. } & \begin{array}{l}\text { Serum Triacylglycerol:- Trinder's } \\ \text { method [18] }\end{array} \\ \text { iii. } & \begin{array}{l}\text { Serum LDL:- } \\ \text { method [19] }\end{array} \\ \text { iv. } & \begin{array}{l}\text { Serum HDL:- } \\ \text { method [19] }\end{array}\end{array}$

\section{Statistical Analysis-}

The values were expressed as mean \pm SD. The statistical data is evaluated by using students unpaired' $t$ 'test. 


\section{Observations and Results}

There was a significant rise in serum hsCRP levels in patients of psoriasis when compared with the controls. ( $<<0.001)$. It was also observed that the levels of serum total cholesterol, LDL, Triacylglycerol were also increased significantly $(\mathrm{p}<0.001)$ as compared with the age and sex matched controls. Serum HDL level was decreased significantly in the psoriasis patients as compared to the control group. [Table1, Graph1]

Table 1: Comparison of serum hsCRP levels and lipid profile in patients of psoriasis and controls

\begin{tabular}{|l|l|l|l|l|l|}
\hline & HsCRP & Total Cholesterol & HDL & LDL & TG \\
\hline Cases & 5.03 & 205.14 & 35.31 & 148.2 & 175.48 \\
\hline Controls & 1.94 & 170.14 & 45.74 & 128.7 & 139.57 \\
\hline P values & $<0.001$ & $<0.001$ & $<0.001$ & $<0.001$ & $<0.001$ \\
\hline
\end{tabular}

Graph 1:- Comparison of levels of serum hsCRP and lipid profile in psoriatic patients and controls
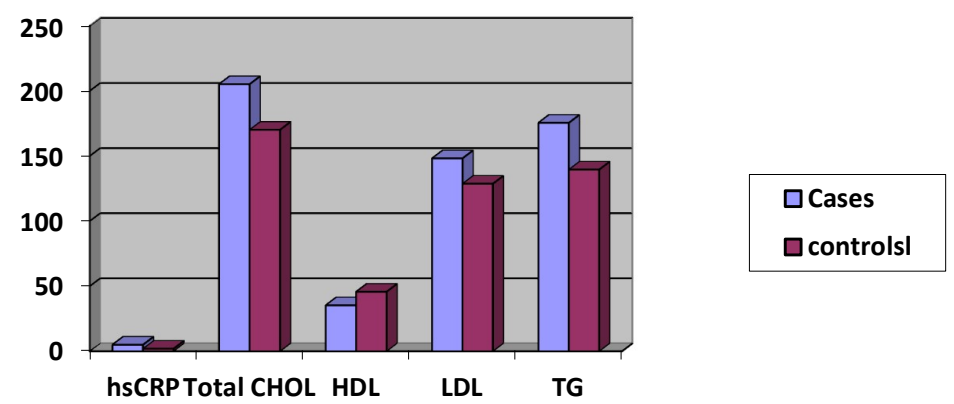

There was a positive correlation between serum hsCRP levels and serum total cholesterol, LDL, Triacylglycerol levels in patients of psoriasis whereas there was a negative correlation between hsCRP levels and serum HDL in patients of psoriasis.

\section{Discussion}

Psoriasis is associated with cardiovascular disease including atherosclerosis and thrombosis (e.g. myocardial infarction) [20]. In the present study, significant dyslipidemia was observed in psoriatic patients as compared to controls [table 1]. This is in concurrence with other studies [21,22]. Dietary factors and socioeconomic status could account for it. The lipid abnormalities seen in psoriasis might facilitate and maintain the inflammatory reaction in the skin [23].

Cholesterol ester transfer protein (CETP) could play a plausible role in increased LDL and decreased HDL-C levels. It transfers the esterified cholesterol from HDL (HDL 2) to VLDL and LDL and replaces it with triacylglycerol. LDL, so altered, is a potential substrate for hepatic lipase.

The enzyme plays a major role in lipoprotein metabolism as a lipolytic enzyme and hydrolyzes triglycerides and phospholipids in chylomicron remnants, IDL, and HDL [24]. The HsCRP levels are also significantly raised in psoriatic patients as compared to controls. Similar findings are observed by Ashish kumar et al[25,26]. CRP itself, beyond serving as a biomarker, may be an active inflammatory protein with a role in endothelial cell dysfunction and vascular remodelling. Psoriasis is characterized by increase in the immunological activity of type 1 helper T cells. Cytokines such as TNF $\alpha$ and interleukin 6 seem to play a central role.

TNF $\alpha$ has also been shown to be a potent activator of terminal kinase, which stimulates activator protein1, a major regulator of proinflammatory activity [23]. There is a positive correlation though not significant between raised serum HsCRP levels and dyslipidemia in patients of psoriasis in this study.

Psoriatic patients already are more prone for CAD and thus raised hsCRP levels make them further more prone for atherosclerotic changes [27] C-reactive protein is an important pathogenic factor for atherosclerosis and 
induces several reactions involved in atherothrombogenesis:

- Activates complement and attacks monocytes

- Incites endothelial dysfunction

- Augments a procoagulant state

- Contributes to plaque instability/rupture

As the level of hsCRP indicates the inflammatory changes occurring at a low level, if estimated early in the process, it would be beneficial. Simple measures like changes in lifestyle, modifications in the diet and exercise may minimize or delay the atherosclerotic changes.

Similar findings were observed by Gelfand, Sommer, Cohen \& other report that have been published previously [21,28.29].

Supplementation of antioxidants to these psoriatic patients may be helpful in curbing the free radicals and minimizing the atherosclerotic changes. Further studies need to be carried out in this regard.

\section{Conclusion}

The present study showed that serum hsCRP levels in psoriasis patients are significantly higher than controls. Thus raised hsCRP can be considered as an added risk factor in Psoriatic patients with regard to coronary artery diseases. Dyslipidemia in psoriatic patients require special attention, and so addition of antioxidants to the conventional ways of treatment may prove therapeutically useful.

Thus, raised serum hsCRP level in association with dyslipidemia in patients of psoriasis should be considered as an added risk factor with a special role of antioxidants in the conventional therapy. Further follow up of such cases can thus be done as a future part of the study.

\section{Acknowledgement}

The authors are thankful to ICMR STS for the financial assistance to carry out this study. The authors are also thankful to Dr Rohini Gaikwad, Professor and Head, Department of Dermatology, MIMER Medical College, Talegaon Dabhade. The authors also thank Mrs Swati Raje, Statistician for helping in the statistical analysis of this project.

Funding: Nil

Conflict of interest: None

Permission from IRB: Yes

\section{References}

1. Friedewald VE, Cather JC, Gelfand JM, Gordon KB, Gibbons GH, Grundy SM, Jarratt MT, Krueger JG, Ridker PM, Stone N, Roberts WC. AJC editor's consensus: psoriasis and coronary artery disease. Am J Cardiol. 2008 Dec 15;102(12):1631-43.

2. Van de Kerkhof PCM. The evolution of the psoriatic lesion. Br JDermatol 2007: 157:4 -15.

3. Schon MP, Boehncke W-H. Psoriasis. N Engl J Med 2005;352:1899-1912.

4. Krueger JG, Bowcock A. Psoriasis pathophysiology: current conceptsof pathogenesis. Ann Rhuem Dis 2005;64:ii30 -ii36.

5. Griffiths CE, Barker JNW. Pathogenesis and clinical features of psoriasis. Lancet 2007: 360:263-271.

6. Lowes MA, Kikuchi T, Fuentes-Duculan J, Cardinale I, Zaba LC,Haider AS, Bowman EP, Krueger JG. Psoriasis vulgaris lesions contain discrete populations of Th1 and Th17 T cells. J Invest Dermatol 2008;128:12071211.

7. Kimball AB, Gladman D, Gelfand JM, Gordon K, Horn EJ, Korman NJ, Korver G, Krueger GG, Strober BE, Lebwohl MG,. National psoriasis foundation clinical consensus on psoriasis comorbidities and recommendations for screening. J Am Acad Dermatol 2008;58:

1031-1042

8. Rocha-Pereira P, Santos-Silva A, Rebelo I, Figueiredo A, Quintanilha A, Teixeira F. Dyslipidemia and oxidative stress in mild and in severe psoriasis as a risk for cardiovascular disease. Clin Chim Acta 2001; 303:3339.

9. Neimann AI, Shin DB, Wang X, Margolis DJ, Troxel AB, Gelfand JM. Prevalence of cardiovascular risk factors in patients with psoriasis. J Am Acad Dermatol 2006;55:829-835.

10. Mallbris L, Granath F, Hamsten A, Ståhle M. Psoriasis is associated with lipid abnormalities at the onset of skin disease. J Am Acad Dermatol. 2006;54:614-621.

11. Ridker PM. A Simple Test to Help Predict Risk of Heart Attack and Stroke.Circulation.2003;107:363-369. 
12. Prodanovich S, Kirsner RS, K revetez JD Association of Psoriasis with coronery artery disease, cerebrovascular \& peripheral vascular disease \& mortality. Arch Dermatol. 2009: 20(470)197413.

13. Pai JK, Pischon T, Ma J, Manson JE, Hankinson SE, Joshipura K, Curhan GC, Rifai N, Cannuscio CC, Stampfer MJ. Inflammatory markers and the risk of coronary heart disease in men and women. N Engl J Med. 2004:351:2599-2610.

14. Ridker PM, Cushman M, Stampfer MJ, Tracy RP, Hennekens $\mathrm{CH}$. Inflammation, aspirin, and the risk of cardiovascular disease in apparently healthy men. N Engl JMed. 1997:336:973-979.

15. National Cholesterol Education Program (NCEP). Expert Panel on Detection, Evaluation, and Treatment of High Blood Cholesterol in Adults (Adult Treatment Panel III). Third Report of the National Cholesterol Education Program (NCEP) Expert Panel on Detection, Evaluation, and Treatment of High Blood Cholesterol in Adults (Adult Treatment Panel III) final report. Circulation. 2002:106; 3143-21.

16. Denka S. Evaluation of a Turbidimetric C-Reactive Protein Assay for Cardiovascular Risk Estimation and Conventional Inflammation Diagnosis. Clin. Chem. 2003: 49: 511-512

17. Myers G, L Kimberly M. A reference method laboratory network for cholesterol : a model for standardisation and improvement of clinical laboratory measurement. Clin Chem. 2000:46: 1762 1772.

18. Henry JB. Clinical diagnosis and management of laboratory methods. 18th edition :W.B. Saunders Philadelphia, 204 211.

19. Greg Miller W. Seven Direct Methods for Measuring HDL and LDL Cholesterol Compared with Ultracentrifugation Reference Measurement Procedures Clinical Chemistry .2010, 56: 977-986.
20. Kurd SK, Richardson S, Gelfand JM. Update on the epidemiology and systemic treatment of psoriasis. Expert Rev Clin Immunol. 2007; 3:171-185

21. Cohen AD, Sherf M, Vidavsky L. Association between psoriasis and the metabolic syndrome. Dermatol. 2008; 216:152-155.

22. Akhyani M, Ehsani AH, Robati RM, Robati AM. The lipid profile in psoriasis: a controlled study. J Eur Acad Dermatol Venereol. 2007; 21:1330-1332.

23. Dreiher J, Weitzman D, Davidovic D, Shapiro J, Arnon DC. Psoriasis and Dyslipidaemia: A Population based Study. Acta Derm Venereol. 2008; 88: 561-565

24. Susan JM, Molly CC, Hal K, John DB, John JA. Selective and independent associations of phospholipid transfer protein and hepatic lipase with the LDL subfraction distribution. J Lipid Res. 2002: 43: 12561263

25. Yiu KH, Yeung CK, Chan HT, Wong RMY, Tam S, Lam KF, Yan GH, Yue WS, Chan HH, Tse HF. Increased Arterial Stiffness in Patients with Psoriasis is Associated with Active Systemic Inflammation. The British Journal of Dermatology. 2011;14(3):514-520.

26. Agravatt AM, Sirajwala HB. A Study of serum hsCRP levels to assess severity in patients with Psoriasis. IJBAR. 2013: 04 (07)460-466

27. Wasunna A. CRP and bacterial infections in preterm infants. Eur .J of aed.1990:149;424-7

28. Gelfand JM, Troxel A, Lewis JD. The risk of mortality in patients with psoriasis: results from a population-based study. Arch Dermatol. 2007: 143:1493-1498

29. Sommer DM, Jenisch S, Suchan M. Increased prevalence of the metabolic syndrome in patients with moderate to severe psoriasis. Arch Dermatol Res. 2006: 298:321-328.

\section{How to cite this article?}

Dhat V, Murhe S, Sontakke A. Serum High Sensitivity CRP (HsCRP) in Psoriasis. Int J Med Res Rev 2014;2(5):409-413. doi:10.17511/ijmrr.2014.i05.02 